\title{
CAMINHOS PERCORRIDOS PELA EDUCAÇÃO AMBIENTAL PARA A VALORIZAÇÃO CULTURAL: O FANDANGO DO LITORAL SUL DE SÃO PAULO E LITORAL NORTE DO PARANÁ
}

\author{
Amilcar Marcel de Souza ${ }^{1}$ \\ Antônio Carlos Diegues²
}

Resumo: O presente relato refere-se a uma narrativa rememorativa de um evento histórico de valorização cultural do Fandango do Litoral Sul de São Paulo e Litoral Norte do Paraná pela realização do I Encontro de grupos de Fandango do Vale do Ribeira e litoral Norte do Paraná realizado em 2003 e sua expressão 14 anos mais tarde. O processo de valorização cultural do Fandango fundamentou-se nas propostas de pesquisa-intervenção-educacional participativa (VIEZZER; OVALLES, 1995) e tendo como objetivo contribuir para a valorização da cultura caiçara. O local desse encontro foi no Parque Estadual da Ilha do Cardoso que está localizado no litoral sul do Estado de São Paulo, em Cananéia, a $272 \mathrm{Km}$ da capital do Estado. Faz divisa com o Estado do Paraná e está inserido na região do Vale do Ribeira. O I encontro de Grupos de Fandango foi realizado nos dias 22 e 23 de fevereiro de 2003. Nesta intervenção foi estimulado o intercâmbio cultural entre os grupos de Fandango, sendo eles comunidade do Itacuruçá (Ilha do Cardoso), Grupo de Fandango de Cananéia, Jovens da Juréia e o Grupo Folclórico Caiçaras do Paraná (Ilha dos Valadares), buscando a valorização de seus hábitos, danças, ritmos locais, dificuldades e sucessos de cada grupo e conhecimentos da biodiversidade ligados a cultura do Fandango. As instituições organizadoras deste evento foram Instituto Ecos da Mata (IEM), Parque Estadual da llha do Cardoso (PEIC) e Núcleo de Apoio a Pesquisa Sobre Populações Humanas e Áreas Úmidas Brasileiras (NUPAUB). Os patrocinadores foram: Fundo de Cultura e Extensão Universitária da Universidade de São Paulo, Consulado Alemão, Instituto Ecos da Mata (IEM), Parque Estadual da Ilha do Cardoso (PEIC) e Instituto de Pesca de Guaragueçaba (IPG). A análise 14 anos mais tarde deste evento de reflexão e discussões com os próprios fandangueiros, foi permeada por análise documental, observação participante e conversas estruturadas com pesquisadores e fandangueiros. Foi possível observar que o Fandango ainda tem dificuldades com sua expressividade, principalmente porque ele é resultado de processos coletivos na comunidade como a colheita de culturas agrícolas, a despesca de cerco entre outros e que por inúmeros motivos que não foi abordado neste trabalho transformaram as comunidades mais individualizadas e comprometendo a execução

1 Engenheiro Florestal Pesquisador do Programa de pós Graduação de Meio Ambiente e Desenvolvimento da Universidade Federal do Paraná e Membro Técnico do Instituto Pro Terra 2 Professor Doutor da Universidade de São Paulo e e Diretor do Núcleo de Apoio à Pesquisa. sobre Populações Humanas em Áreas úmidas Brasileiras NUPAUB/USP. 
de rodas ou bailes de Fandango. Por outro lado, foi observado que o Fandango está "vivo", tendo várias ações nesta região estudada como protagonistas desta manutenção cultural que vão desde políticas públicas até ações individuais.

Palavra Chave: Fandango; Educação Ambiental; Valorização Cultural.

Abstract: The present report refers to a narrative reminiscent of a historical event of cultural valorization of the Fandango of the South Coast of São Paulo and the North Coast of Paraná for the holding of the First Meeting of Fandango groups from Vale do Ribeira and the North coast of Paraná held in 2003 and its expression 14 years later. The process of cultural valorization of Fandango was based on the proposals for participatory educational-intervention-research (Viezzer \& Ovalles, 1995) and with the objective of contributing to the valorization of caiçara culture. The place for this meeting was at the Ilha do Cardoso State Park. which is located on the south coast of the state of São Paulo, in Cananéia, $272 \mathrm{~km}$ from the state capital. It borders the State of Paraná and is located in the Vale do Ribeira region. The first meeting of Fandango Groups was held on February 22 and 23, 2003. In this intervention, cultural exchange between Fandango groups was stimulated, being the community of Itacuruçá (Ilha do Cardoso), the Fandango Group of Cananéia, Youth from Juréia and the Caiçaras do Paraná Folkloric Group (Ilha dos Valadares), seeking to enhance their habits, dances, local rhythms, difficulties and successes of each group and knowledge of biodiversity linked to Fandango culture. The organizing institutions for this event were Instituto Ecos da Mata (IEM), Ilha do Cardoso State Park (PEIC) and Support Center for Research on Human Populations and Brazilian Wetlands (NUPAUB). The sponsors were: Culture Fund and University Extension of the University of São Paulo, German Consulate, Ecos da Mata Institute (IEM), Ilha do Cardoso State Park (PEIC) and Guaragueçaba Fisheries Institute (IPG). The analysis 14 years later of this event of reflection and discussions with the fandangueiros themselves, was permeated by documentary analysis, participant observation and structured conversations with researchers and fandangueiros. It was possible to observe that Fandango still has difficulties with its expressiveness, mainly because it is the result of collective processes in the community such as the harvesting of agricultural crops, the siege harvesting among others and that for countless reasons that were not addressed in this work transformed the communities more individualized and compromising the execution of circles or Fandango balls. On the other hand, it was observed that Fandango is "alive", with several actions in this region studied as protagonists of this cultural maintenance, ranging from public policies to individual actions.

Key word: Fandango; Environmental Education; Cultural Valorization. 


\section{Introdução: O aspecto inovador do I Encontro reunindo fandangueiros do Paraná e SP}

O I Encontro de Grupos de Fandango da llha do Cardoso foi realizado no Parque Estadual da Ilha do Cardoso (PEIC), localizado no litoral sul do Estado de São Paulo, em Cananéia, a $272 \mathrm{Km}$ da capital do Estado. Faz divisa com o estado do Paraná e está inserido na região do Vale do Ribeira. No Parque são encontrados todos os tipos de vegetação da Mata Atlântica costeira: vegetação pioneira de dunas, manguezal, floresta pluvial tropical de planície litorânea e floresta pluvial tropical de encosta da Serra do mar, além de vegetação altitude e algas marinhas na praia e costões rochosos.

A ideia de que a preservação de um ecossistema natural protegido está baseada na eliminação completa da intervenção humana pode gerar efeitos negativos a longo prazo e vem sendo discutida com intensidade e frequência cada vez maiores. Assim sendo, o enfoque da conservação deveria implantar alternativas de desenvolvimento que garantam a conservação da biodiversidade e o consequente desenvolvimento sustentável da humanidade (Diegues, 2005).

Os conhecimentos da cultura caiçara presentes fortemente nesta região em que o trabalho foi desenvolvido, geralmente são passados de geração em geração de pai para filho ou pelos idosos que possuem um grande conhecimento de pesca, ciclos da lua, plantas medicinais e técnicas de caça. Nesta relação, afloram muitos outros aspectos tradicionais da cultura caiçara, como a música, a religião e as danças, sendo todas enfocadas na forma de verdadeiros rituais de agradecimentos ou pedidos de uma boa colheita e fartura para toda a comunidade.

Mas esses costumes e práticas estão desaparecendo, uma vez que diversos fatores influenciam na desvalorização cultural dessas comunidades inseridas neste contexto de Mata Atlântica, entre eles destaca-se a urbanização e o turismo mal planejado, além das práticas preservacionistas que excluem as praticas humanas em áreas de Unidades de Conservação.

Dessa forma, o Fandango que é objeto protagonista deste trabalho também vem sendo extinto, tendo que ele é uma expressão cultural ligada aos mutirões de plantio e colheita de roças agrícolas tradicionais sendo um importante ritual rural de coletividade e ajuda mútua para os afazeres da lavoura os quais finalizavam com a confraternização chamada Fandango.

Com as proibições às práticas agrícolas tradicionais estabelecidas pelas regras de conservação, essa expressão de identidade do caiçara a sua paisagem se encontra quase extinta nesta região, tendo somente alguns atores sociais isolados, geralmente de mais idade, e que muito raramente se reúnem para tocar e cantar Fandango. 


\section{Localização do PEIC e das comunidades participantes}

O encontro de intercâmbio e valorização cultural do Fandango ocorreu no Parque Estadual da Ilha do Cardoso no Estado de São Paulo (PEIC) e as comunidades e grupos participantes foram a comunidade do Itacuruçá (Ilha do Cardoso), Grupo de Fandango de Cananéia/SP, Jovens da Juréia de Bertioga/SP e o Grupo Folclórico Caiçaras do Paraná (Ilha dos Valadares) de Paranaguá/PR.

Na Figura 1, está apresentada a localização geral do PEIC, na Figura 2 a localização dos grupos comunidades do Itacuruçá, Grupo de Fandango de Cananéia/SP, Jovens da Juréia de Bertioga/SP e na figura 03 a localização do Grupo Folclórico Caiçaras do Paraná (Ilha dos Valadares) de Paranaguá/PR.

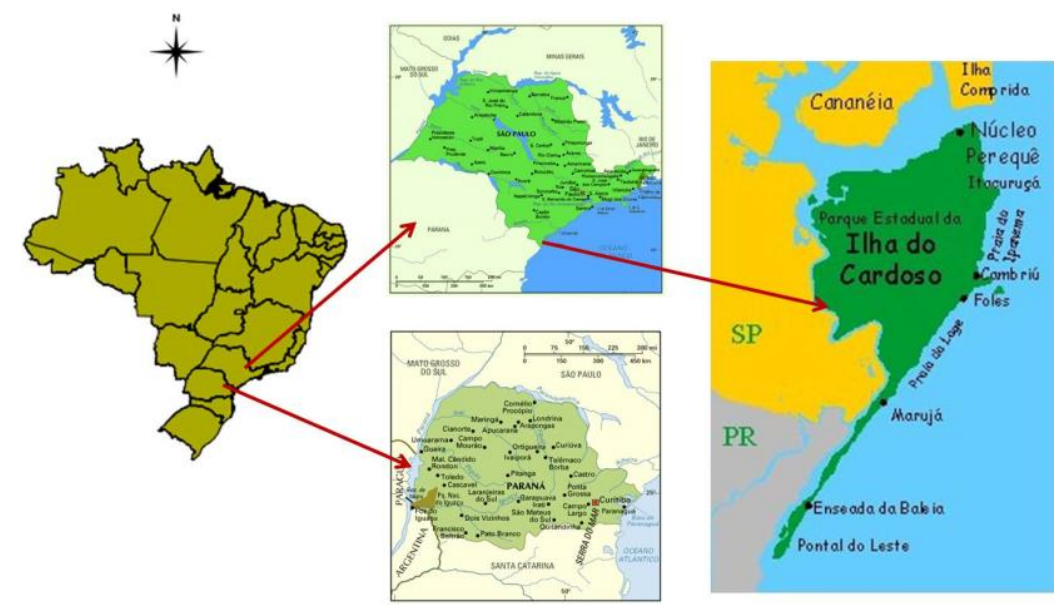

Figura 1: Localização do PEIC e dos Estados de São Paulo e Paraná. Fonte: Souza (2019).

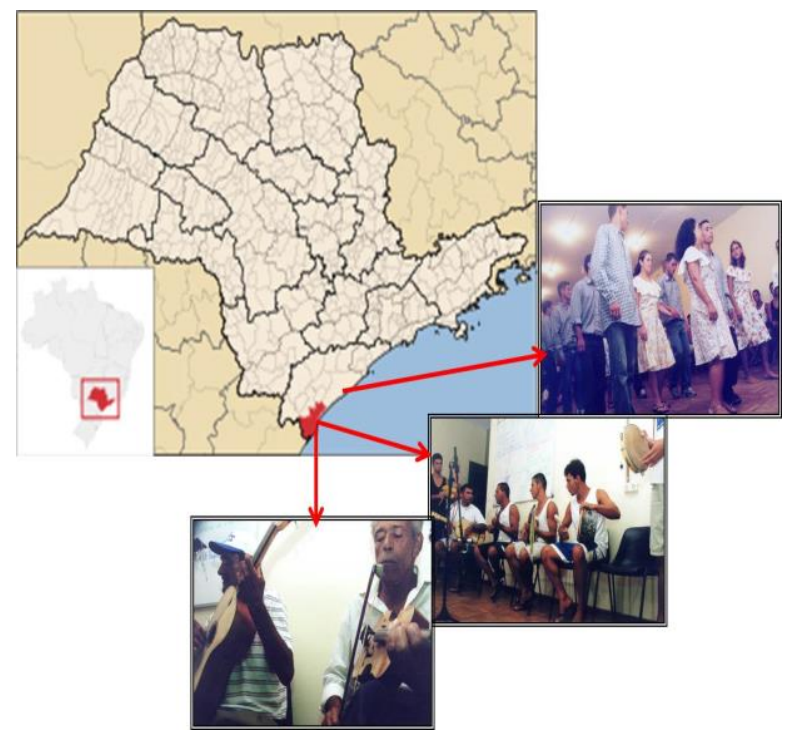

Figura 2: localização dos grupos Jovens da Juréia de Bertioga/SP (1) comunidade do Itacuruçá

(2) e Grupo de Fandango de Cananéia/SP (3).

Fonte: Souza (2019). Fotos:Souza (2003) 


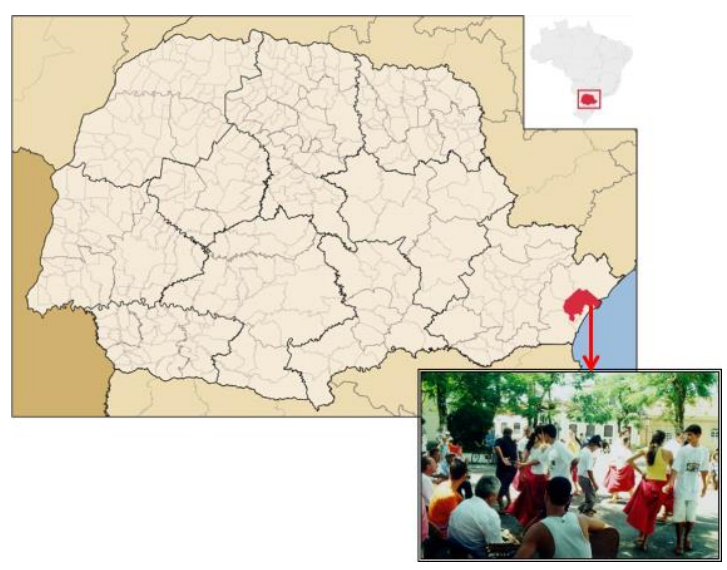

Figura 3: Localização do Grupo Folclórico Caiçaras do Paraná (Ilha dos Valadares) de Paranaguá/PR. Fonte: Souza (2019). Foto: Souza (2003).

\section{O que é o Fandango e seu papel nas comunidades no passado e no presente}

Dentre tantas práticas culturais dos caiçaras, está o Fandango que é uma festa folclórica típica dos caboclos e pescadores da faixa litorânea sul do Rio de Janeiro em Paraty, Sul de São Paulo e norte do Paraná. Rico em repertório de canções e ritmos, o Fandango é uma reunião de várias danças que encerram ainda autêntica poesia cabocla nos cantos que as acompanham. A melodia e os versos entoados pelos violeiros e pelo coro, contém originalidade, lirismo e humor, levando-nos a admirar a imaginação e a sensibilização do nosso caboclo (GRAMANI, 2009).

Sua coreografia é variada e difícil, exige técnica, atenção, agilidade, preparo e calçados especiais para o sapateado. As mulheres valseiam arrastando os pés, atentas as evoluções, enquanto os homens sapateiam num ritmo certo, seguindo o acompanhamento das violas, rabecas, pandeiros e bumbos. O canto é puxado pelos violeiros ou cantadores a duas vozes com letras tradicionais ou improvisadas (GRAMANI, 2009).

A sociabilidade é uma das mais importantes características socioculturais do Fandango, uma vez que ele é o momento celebrativo e de confraternização dos momentos sociais da comunidade como por exemplo campeonatos de futebol, do carnaval, das romarias, festas religiosas, entre outros (MARTINS, 2006).

O Fandango Caiçara presentes no litoral sul de São Paulo e Norte do Paraná tem como características a complexidade em sua expressão seja na dança ou na música. Ele envolve várias possibilidades de execução de instrumentos musicais, melodias, versos e coreografias, sempre tendo a paisagem e histórias cotidianas como inspiradoras. Aglutina danças em pares, nos quais podem ser utilizados tamancos de madeira para fazer o batido, além de música executada que é sonorizada por instrumentos feitos por artesãos 
locais que constroem de forma artesanal a viola branca ou de Fandango, a rabeca e o adufo (IPHAN, 2011).

\section{Sobre os Trajes e instrumentos}

O traje é o mais barato possível, sendo chita, algodão e brim.

- Para os homens o traje é calça de brim e camisa chita estampada, seu tamanco é feito de cepo de laranjeira ou de ipê por produzir mais som, confeccionado pelo próprio dançador.

- Para as mulheres o traje é saia de chita, bem rodada e bata branca presa a cintura ou então vestido todo estampado, cabelo simples com penteado ou sem.

"Esse é o traje do caboclo que é pobre e humilde mas se veste muito bem para as festas"

Seu Janjão de Cananéia no Encontro de Fandango da Ilha do Cardoso em 2003.

Os instrumentos utilizados foram viola de 5 e 11 cordas, rabeca de 3 e 4 cordas, cavaquinho, pandeiro e bumbo.

As violas presentes neste encontro eram feitas de Caixeta, Caroba e Cambará com enfeites de Cedro, Bejaru e Canela. Suas tarrachas e cavaletes eram todas de Canela.

As rabecas presentes neste encontro eram de Caixeta ou Cedro de tamanho que variava de pequena a grande.

As comunidades que participaram deste encontro estão todas localizadas em áreas de mata atlântica sujeitas às inúmeras restrições ambientais, as quais proíbem muitas práticas tradicionais como roçado, confecção de canoas e outros artefatos que afetam diretamente o Fandango. Com isso, em muitas comunidades o Fandango não é mais praticado ficando só em relatos das pessoas mais antigas.

Por outro lado, um grande movimento em prol da valorização do Fandango já está estabelecido, no entanto, com ações isoladas (CORREA, 2006). Este encontro foi uma primeira tentativa de promover o intercâmbio cultural resgatando letras e danças, bem como iniciar uma melhor organização entre os grupos e estabelecer compromissos na busca do fortalecimento desse movimento que acontece no litoral sul de São Paulo e Norte do Paraná. A relevância da presente proposta organizada por alunos de graduação em engenharia florestal da ESALQ/USP pelo NUPAUB/USP no ano de 2003 encontrou-se no objetivo de deflagrar o sentimento de pertencimento ao seu lugar (AB SABER, 1991) fomentando o espirito de atuar pela melhoria de seu espaço (SEGURA, 1999), contribuindo para uma mudança comportamental 
diante da situação atual de desrespeito e descaso ambiental, social e cultural, através da Educação Ambiental, enfatizando o resgate da cultura caiçara.

O resgate cultural é urgente para evitar a perda deste complexo conhecimento tradicional caiçara acerca da musicalidade representada pelos instrumentos, danças e vestimentas e sua relação com a natureza e manutenção da coletividade em comunidades locais. $O$ conhecimento tradicional definido por Diegues (2004) é o saber e o saber-fazer a respeito do mundo natural e sobrenatural.

\section{Caminhos Metodológicos: Os preparativos para o Encontro, pessoas e instituições envolvidas}

Nessa perspectiva, alunos do curso de engenharia florestal da ESALQ/USP que estagiaram no programa de verão do Parque Estadual da llha do Cardoso em 2003 perceberam e identificaram em seu cotidiano na convivência com alguns importantes atores sociais moradores da llha do Cardoso que tocavam Fandango como o Sr. Antonio Neves, Seu Zé, os irmãos Leonildo e Zé Pereira, entre outros que essa expressão cultural é extremamente relevante para a identificação caiçara e consequentemente para a conservação dos recursos naturais, uma vez que o seu modo de vida está intimamente relacionado com os processos da natureza e o seu manejo é dentro dos limites da sustentabilidade ambiental (DIEGUES, 2013).

Sendo assim, iniciou uma pesquisa-ação dentro das atividades do estágio no final de dezembro de 2002, com o apoio do PEIC, visando contribuir para produção de conhecimento e valorização da cultura das comunidades tradicionais viventes na Floresta Tropical Atlântica do Estado de São Paulo e Paraná, que possam ser multiplicados no sentido da construção de sociedades sustentáveis.

Os resultados desta pesquisa ação foram organizados em um relatório e apresentado para a direção do PEIC e em reuniões dos alunos da ESALQ/USP que eram estagiários surgiu a ideia da realização de um encontro de Fandangueiros com a perspectiva de: Promover intercâmbio cultural entre comunidades tradicionais no Vale do Ribeira; Contribuir para a valorização cultural e ambiental da Floresta Tropical Atlântica; Realizar trabalho de pesquisa de caráter ambiental e cultural junto às comunidades tradicionais da Floresta Tropical Atlântica do Estado de São Paulo e Paraná; Estimular o sentimento de pertença e co-responsabilidade diante das questões ambientais e culturais da Floresta Tropical Atlântica; Disponibilizar repertório no campo socioambiental que possibilite a reflexão sobre as origens e consequência dos problemas socioambientais da Floresta Tropical Atlântica (FALEIROS, 2003).

Os alunos envolvidos neste processo eram alunos da ESALQ/USP e foram buscar auxilio metodológico junto ao NUPAUB/USP.

Essa proposta foi enviado ao Fundo de Cultura e Extensão Universitário da USP pelos alunos Amilcar Marcel de Souza e Karine Faleiros juntamente 
com a orientação do professor Dr. Antonio Carlos Diegues do NUPAMP/USP e aprovado para sua execução no ano de 2003. Dessa forma, o caminho metodológico foi construído juntamente com o NUPAUB/USP e foi baseado na pesquisa-intervenção-educacional que fundamenta-se nos princípios das metodologias qualitativas e mais especificamente na pesquisa-ação. De acordo com Patton (1980), citado por Brito (1998), metodologia de pesquisa qualitativa contribui para as comunidades desenvolverem programas que auxiliem no entendimento da realidade, aflorem os conflitos e busquem soluções para os problemas.

A pesquisa-ação se apresenta neste trabalho como uma metodologia de interdisciplinaridade associada a diversas formas de ação coletiva que foi orientada em função da resolução de problemas ou de objetivos de transformação (DENZIN; LINCOLN, 1994).

Essa metodologia auxiliou na proposta deste trabalho para buscar um aprofundamento sobre a questão da participação das comunidades na busca do resgate cultural, intercâmbios entre as comunidades e busca da melhoria da qualidade de vida. As atividades propostas no presente trabalho foram de fundamental importância da ação local (Franco 1995), quando se pensa em melhorias do espaço comum, e mais do que isso, a valorização da passagem do saber e entender para as futuras gerações, estimulando a vontade de buscar soluções e propor ações.

Para tanto, elaborou-se uma programação com temas transversais sobre cultura e meio ambiente (PCN, 1998) para a melhor coordenação, discussões, trocas de experiências musicais, dificuldades e sucessos de cada grupo e uma atividade conhecida como chuva de ideias, na qual, foram levantadas inúmeras ações em prol do resgate cultural do Fandango.

\section{Programação do encontro e sua perspectiva da valorização Cultural do fandango}

Essa iniciativa tinha toda a estrutura intelectual teórica e metodológica, além das parcerias feitas entre a Universidade de São Paulo, PEIC e as comunidades, mas faltavam os recursos financeiros para operacionalizar esta mobilização da valorização cultural. As buscas dos recursos foram feitas junto ao consulado Alemão em São Paulo que prontamente aceitou a proposta de custear o transporte e alimentação das comunidades até o PEIC e como contrapartida os parceiros colocavam suas estruturas técnicas a disposição.

Dessa forma, entre os dias 29-31 de março de 2003 foi realizado no Parque Estadual da llha do Cardoso, Cananeia/SP o evento histórico I Encontro de Fandango das comunidades tradicionais da Floresta Tropical Atlântica do Estado de São Paulo e Paraná.

A programação do encontro seguiu o seguinte roteiro: 


\section{-Sábado (22 de fevereiro de 2003)}

9 até $12 \mathrm{~h}$ - Previsão de chegada dos grupos residentes fora de Cananéia (local: Base do Parque Estadual da Ilha do Cardoso);

12h - Saída de barco para o Núcleo Perequê (local: Porto do PEIC;

13 até 14:30h - Almoço (local: refeitório do Núcleo Perequê);

15:15h - Abertura do Evento (local: Auditório do Núcleo Perequê;

16:00h - Troca de Experiências entre os grupos de Fandango - Apresentação de cada grupo, ritmos musicais e suas danças (local: Auditório do Núcleo Perequê;

18:00h - Encerramento do Período (local: Auditório do Núcleo Perequê;

18:30 até 20h - Apresentação dos Grupos de Fandango e grande Baile (local: Auditório do Núcleo Perequê;

\section{Domingo (23 de fevereiro de 2003)}

8 até $9 \mathrm{~h}$ - Café (local: Refeitório do Núcleo Perequê);

9:30 até $12 \mathrm{~h}$ - Discussão geral para articulações do resgate cultural e encerramento do evento (local: Auditório do Núcleo Perequê)

12:30h - Almoço (local: refeitório do Núcleo Perequê)

$15 \mathrm{~h}$ - Apresentação na Praça Martim Afonso de Souza de Cananéia.

Os mestres de cerimônia de abertura foram:

- Karine Faleiros (Instituto Ecos da Mata)

- Marcio Roberto (Instituto Ecos da Mata)

- Marcos Campolim (PEIC)

- Antonio Diegues (NUPAUB)

A moderação das atividades do dia 22 foi coordenada por Karine Faleiros (Instituto Ecos da Mata), e no dia 23 a moderação foi coordenada por Amilcar Marcel e Flávio Cremonesi (Instituto Ecos da Mata).

\section{O evento: grupos de Fandango participantes: temas apresentados e discutidos no encontro}

O Primeiro Encontro e Fandango do Parque Estadual da Ilha do Cardoso reuniu aproximadamente 70 pessoas, que são apresentadas a seguir.

- Associação Jovens da Juréia: Anderson do Prado, Ilson de Lima, Charles do Prado, André Luis de Souza Prado, Heber do Prado, Pedro do Prado, Glória do Prado, Zeli Aparecida de Souza, Cleiton do Prado, Adriana Alves Carneiro, Marcos Vinicius de Souza Prado, Alan Alves Carneiro, Silmara do Prado, Wellington Carneiro de Souza Gomes, Vanderléia de Souza, Maridalva Sardinha, Zilda de Lima do Prado, Miguel do Prado, Rodrigo do Prado, Leandro 
do Prado, Zenelio Pereira Gomes, Ana Claudia de Souza Prado, Gilson do Prado, Ceiton de Souza Fortes, Edno Luis do Prado, Renato Pereira, Pedro Marçal do Prado, Renival Alves e Dauro Marcos do Prado.

- Grupo de Fandango de Cananéia: Laudelino Carpinteiro, Hugo de Almeida, Beto Pereira, João Firmino e João Cassiano Martins (Janjão)

- Comunidade do Itacuruçá: Vadico, Elvaristo, Adriano, Aldemir, Thiago, Juninho e Felipe.

- Grupo Folclórico Caiçaras do Paraná: Músicos: Gerônimo dos Santos, Romão Luis do Nascimento, Manoel Fernandes e Gabriel Martins;Dançarinos e Dançarinas: Annete Terezinha, Donaide Pontes do Rosario, Ana Paula V. Guimarães, Elen Elias, Marcele Feliciano, Karine Cabral, André Luis, Erick Braian, Luciano Gomes, Marcio Teodoro dos Santos, Michel Batista, Rogério Luis Silva, Sandro Mauro Teixeira; Mestres de roda: Balduíno e Jose Cardoso dos Santos.

- Instituto Ecos da Mata: Karine Silva Faleiros, Joana de Barros Amaral, Marcio Sartorio, Amilcar Marcel de Souza, Flavio Cremonesi, Joana Mattei Fagin, Mariana Prado.

- Parque Estadual da Ilha do Cardoso: Marcos Campolim, Isadora Parada, Beatriz, Ilzo, Jorge e Zico.

As discussões permearam pelos seguintes temas:

- como está o Fandango na comunidade;

- participação dos jovens;

- periodicidade do Fandango;

- quais os principais ritmos tocados;

- como as danças são organizadas;

- transmissão da cultura e dos valores;

- características dos instrumentos de cada grupo.

\section{Resultados}

\section{Apreciação do encontro por seus participantes}

Algumas falas foram coletadas através de entrevistas e anotações quando faladas para o coletivo nos momentos de debates e reflexões no encontro que representam os diversos atores sociais presentes. Nessas falas estão membros das comunidades caiçaras, Universidade de São Paulo, da sociedade civil e do poder público estadual. 
Nesse primeiro conjunto de relatos através das falas foi coletado e observado no início do encontro onde é fácil perceber a expectativa e o desejo da valorização do Fandango.

"Estamos orgulhos pela troca de experiências. É uma vontade muito antiga e grande de expor a dança e a música aqui no PEIC. Tenho certeza de que o Fandango nunca vai acabar".

Marcos Campolim: Gestor do Parque Estadual da llha do Cardoso representante do Instituto Florestal do Estado de São Paulo.

"Estamos com muita vontade de saber porque o Fandango está acabando. Devemos ao final desse encontro propor um diagnóstico para elaboração de um plano para o fortalecimento dessa cultura".

Marcio: Representante da sociedade civil do Instituto Ecos da Mata.

"A partir de 69 a situação dos caiçaras ficou muito difícil, de Paraty ao Paraná. A música se mostra como um elemento de forte resistência de valorização da cultura e estabelecimentos de sentimentos de pertencimento e identificação com suas tradições".

Diegues: professor Doutor do NUPAUB, Universidade de São Paulo.

A partir da abertura foi permitido aos grupos explanarem sobre os temas abordados, já descritos acima.

"Na comunidade do Itacuruçá as atividades de trabalho são pesca, turismo e guarda-parques. O Fandango não tem hora para ser tocado. É só estar todos juntos que tocamos. $O$ apoio é do PEIC e do consulado da Alemanha, sem apoio algum da prefeitura. Antigamente o Fandango era uma celebração de um dia de mutirão, era uma forma de pagamento pelo trabalho que podia ser colheita ou plantio, normalmente de milho, mandioca, cara, melancia, feijão, amendoim etc. Esses mutirões eram muito importantes para essa cultura. Atualmente, o Fandango está crescendo aqui na comunidade, estamos aprendendo ritmos e toques que não conhecíamos, buscamos com os mais velhos daqui mesmo ou de outras comunidades e também assistimos apresentações de outros grupos da região para aprendermos."

Felipe: Representante da Comunidade caiçara do Itacuruçá, Ilha do Cardoso. 
Abaixo, seguem duas importantes falas captadas no encontro que sinalizam as dificuldades da manutenção do Fandango e o difícil trabalho da valorização e manutenção cultural.

"Aqui em Cananéia estamos lutando muito para conseguir manter o Fandango. Hoje tem que fazer reunião, antigamente era por intermédio dos mutirões. Infelizmente Cananéia não tem apoio da prefeitura. Muitos tocadores nem se interessam em se juntar para tocar, acho que sentem vergonha. Nem temos um grupo definido, é uma luta para acharmos rabequeiros e cantadores. Hoje em dia os jovens não se interessam e nem sabem o que é o Fandango, suas danças e seus ritmos. Aqui em Cananéia os instrumentos são feitos de caixeta, canela, cedro, normalmente por um "fabriqueiro" responsável por sua fabricação. As letras das músicas continuam as mesmas, mas sempre alguém faz alguma nova."

Sr. Janjão: Representante do Grupo de Fandango Caiçara de Cananéia.

"Aqui na Juréia a nossa casa virou Parque e tivemos que sair. Fomos expulsos e tivemos vários conflitos com o estado. Atualmente, trabalhamos de pedreiros, veranistas e fazemos artesanato de caixeta. Normalmente o Fandango é apresentado nas festas na cidade ou em encontros como este. Também fazemos o Fandango quando tem alguma comemoração aqui na comunidade. Não temos nenhum apoio da prefeitura e lutamos pela própria vontade. O nosso grupo se formou a poucos anos e isso foi muito bom, pois sentimos que a reunião no Fandango provocava um espírito de muita união e percebemos que a participação de todos começamos a resolver os nossos problemas com mais facilidade. Estamos fazendo algumas ações para manter essa cultura. Uma delas é um curso de rabeca e viola na Escola Caiçara da Juréia, com atividades durante de 2 meses". Na fala abaixo do Grupo Folclórico Caiçaras do Paraná, captada no encontro é possível observar que as iniciativas da valorização e manutenção do Fandango estão surgindo mesmo que ainda de forma isoladas. A busca do aprendizado e o envolvimento de diferentes idades somado com uma politica publica de valorização cultural, apontam para um caminho promissor para esta região de ocorrência do Fandango.

Dauro: Representante da Associação dos Jovens da Juréia. 
"O Grupo Folclórico Caiçaras do Paraná é da llha dos Valadares e é formado por estudantes professores e aposentados. Temos ensaios periódicos aos domingos. Lá na Ilha dos Valadares existem outros grupos que surgiram em função do interesse do ex-prefeito e com a lei de incentivo à cultura local. O Caiçaras do Paraná tem 1 ano e meio, surgiu de um grupo maior e atualmente foi reduzido. O que mantém o grupo é uma empresa, através dessa lei de incentivo a cultura. Um espaço bem legal foi feito em Paranaguá e é chamado a Casa do Fandango, onde geralmente o Fandango é tocado e dançado. O nosso grupo toca atualmente o Dom Dom e a Chamarrita e fazemos o batido com os tamancos. Estamos tentando tocar a Querumana, mas ainda estamos aprendendo, pois é um ritmos muito difícil. Talvez umas das causas do Fandango estar em uma fase bastante difícil, onde poucas pessoas se interessam é em função de hoje existirem muitas outras atrações (boates, bares, bailes etc). Antigamente os jovens eram mais interessados no Fandango, eram mais integrados com os pais, e ao contrario hoje a relação pai e filho não é mais tão intensa Estamos nos mantendo por nossa própria vontade e fomos atrás de patrocínio, além da ajuda da prefeitura que libera verba através de prestação de contas".

Marcio: Representante do Grupo Folclórico Caiçaras do Paraná.

\section{Propostas sugeridas pelos Fandangueiros}

As propostas de ações em prol do Fandango foram bastante discutidas entre os grupos através de uma plenária geral, onde foram levantadas algumas ideias. São elas:

1) Promover mais encontros. As possíveis datas são:

- Festa do Mar em Cananéia mês de julho de 2003.

- Dia do Fandango em Paranaguá 26/09/03.

- Fevereiro de 2004 em Iguape/SP.

- Festa das Nações de Pariquera-Açú/SP, mês de maio.

2) Pressionar as autoridades de Cananéia para a construção da Casa do Fandango.

3) Promover encontros entre os grupos com oficinas de danças, musicas e confecção de instrumentos (rabeca e viola caiçara).

4) Convidar outros grupos para participarem dos próximos encontros.

5) Formalização dos Encontros de Fandango através de documentos publicados e página na Internet.

6) Fortalecimento dos grupos através dos intercâmbios culturais.

7) Manifestações que despertem a simpatia da comunidade. 
8) próxima festa do mar, vender algo típico para arrecadar dinheiro.

9) Promover o intercambio da lei municipal de incentivo cultural de Paranaguá com outros municípios (Cananéia, Iguape e Pariquera-Açú).

10) Desenvolver ações para o crescimento dos grupos dentro das cidades.

11) Cada grupo se organizar para falar com os prefeitos e vereadores.

\section{Avaliação do encontro pelos participantes}

O I Encontro de Fandango das comunidades tradicionais da Floresta Tropical Atlântica do Estado de São Paulo e Paraná, foi um evento histórico para a busca da valorização do Fandango, seja visto que nos anos posteriores inúmeras ações de valorização e resgate estão sendo desenvolvidas nesta região, mantendo ainda que de forma pontual o Fandango presente na identidade caiçara.

Inúmeros pensamentos e falas a respeito do Fandango apareceram de forma muito agradável e emocionante, envolvendo desde os mais jovens que se expressaram de maneira brilhante e esperançosa, até os mais velhos que com toda sua sabedoria, calmamente relatavam como era o Fandango e todas suas mudanças ao longo da história em função de inúmeros conflitos com a legislação ambiental, criação de parques estaduais e federais, especulação imobiliária, etc.

Esses relatos podem ser observados com as falas dos mestres fandangueiros e pesquisadores.

"Este encontro foi muito proveitoso, com muitos aprendizados e ensinamentos sobre os instrumentos e conhecer outros estilos. Sensacional"

Marcio: Grupo Folclórico Caiçaras do Paraná (Paranaguá).

"É indescritível a sensação de ver que o Fandango está também em outros lugares. è gostoso conviver com pessoas que desenvolvem a mesma cultura. O nosso grupo esta muito acostumados com o palco e perde-se um pouco a sensibilidade pela cultura, então estar com o Fandango mais informal é muito bom ".

Luciano: Grupo Folclórico Caiçaras do Paraná (Paranaguá),

"Estamos muito felizes em ter participado, poder passar um pouco dos nossos conhecimentos e receber dos outros grupos. Ah! e agora queremos aprender o sapateado com o pessoal do Paraná".

Dauro: Representante do grupo Jovens da Juréia. 
“ Estamos bastante felizes por esse encontro e não sabíamos que tem pessoas engajadas nessa cultura, precisamos muito destas experiências, pois o grupo é novo. Estamos muito interessados em aprender dançar o passadinho, o batido e a dança de São Gonçalo".

Felipe: Representante da Comunidade do Itacuruçá/llha do Cardoso.

“ Gostaria de agradecer o pessoal da Juréia que estimulou o grupo do itacuruçá. O Parque Estadual da Ilha do Cardoso é uma área protegida, e pra preservar todos seus recursos naturais devemos valorizar a cultura local, é impossível desvincular o ambiente das pessoas".

Marcos Campolim: Gestor do Parque Estadual da Ilha do Cardoso representante do Instituto Florestal do Estado de São Paulo.

\section{Importância do encontro para o registro do Fandango como Patrimônio Cultural Brasileiro pelo IPHAN e para as atividades do Museu Vivo do Fandango}

Todo esse processo deste encontro histórico na llha do Cardoso sem dúvida fortaleceu os movimentos isolados dos grupos e comunidades presentes neste encontro da valorização do Fandango para um caminho de conexão entre eles mesmos e a formação de novos grupos e também a elaboração de politicas públicas municipais e federal como o reconhecimento do Fandango como Patrimônio Cultural Brasileiro pelo IPHAN.

$\mathrm{Na}$ ocasião deste encontro na Ilha do Cardoso a Associação Cultural Caburé teve contato com essa iniciativa e tempos mais tarde criou o projeto "Museu Vivo do Fandango" que é um grande exemplo de projeto de valorização cultural desenvolvido sob a forma de pesquisa-ação participante envolvendo comunidades caiçaras do litoral das regiões Sul e Sudeste do Brasil. Essa iniciativa tem preservado a prática do Fandango Caiçara em diversas comunidades caiçaras dessas regiões.

O projeto Museu Vivo do Fandango, segundo o Dossiê de Registro do Fandango Caiçara (2011) observou e constatou que a prática do Fandango, estava desarticulada e ficando bastante rara. Desde 2005, a pesquisa mobilizou inúmeros fandangueiros da região e uma importante ação foi a iniciativa da realização de Encontros de Fandango e Cultura Caiçara que foram realizados nos anos de 2006 e 2008 na cidade de Guaraqueçaba/PR. A primeira edição contou com financiamento do Programa Petrobras Cultural e apoio da Prefeitura Municipal de Guaraqueçaba. A gestão foi feita pela equipe envolvida com o projeto Museu Vivo do Fandango (Associação Cultural Caburé/RJ) e por um coletivo de associações culturais da região. 
No II Encontro de Fandango e Cultura Caiçara realizado em julho de 2008 no município de Guaraqueçaba/PR, foi viabilizada pelo Prêmio Avon Cultura de Vida, também com apoio da Prefeitura de Guaraqueçaba, e gerida pela Associação de Fandangueiros de Guaraqueçaba, juntamente com o coletivo de associações, foi submetido de maneira oficial ao Iphan o pedido de registro do Fandango como um bem cultural de natureza imaterial de acordo com o previsto no Decreto 3.551, de 4 de agosto de 2000.

Esse pedido de registro teve o aceite em novembro de 2008, através da Nota Técnica n.21 GR/DPI/Iphan pela Comissão do Patrimônio.

Os grupos que fazem parte do coletivo de associações e que manifestaram o pedido de registro foram: Associação de Cultura Popular Mandicuéra/PR, Ponto de Cultura Caiçaras/SP, Associação de Fandangueiros de Guaraqueçaba/PR, Associação Jovens da Juréia/SP e Rede Cananéia/SP. Ressalta-se que são os mesmos grupos que participaram do encontro no Parque Estadual da llha do Cardoso em 2003.

Em 2012, finalmente o Fandango Caiçara foi registrado pelo IPHAN através do processo administrativo 01450014268/2008-59, aprovado na 71 reunião do Conselho Consultivo do Patrimônio Cultural realizada em 29/11/2012 e lavrado pela certidão IPAHAN de 6/3/2013 como -

"uma expressão musical-coreográfica-poética e festiva, cuja área de ocorrência abrange o litoral sul do Estado de São Paulo e o litoral norte do Estado do Paraná. Essa forma de expressão é um dos bens imateriais que compõe o Patrimônio Cultural do Brasil. Possui uma estrutura bastante complexa e se define em um conjunto de práticas que perpassam o trabalho, o divertimento, a religiosidade, a música e a dança, prestígios e rivalidades, saberes e fazeres. O Fandango Caiçara se classifica em batido e bailado ou valsado, cujas diferenças se definem pelos instrumentos utilizados, pela estrutura musical, pelos versos e toques."

\section{Encontros subsequentes englobando grupos de outras cidades, do litoral norte de SP}

- Quinze (15) Anos mais tarde: Como anda a expressão cultural do Fandango?

Em um encontro no NUPAUB/USP com o professor Antônio Carlos Diegues no Programa de Pós Graduação em Desenvolvimento e Meio Ambiente da UFPR - PPGMADE/UFPR com o pesquisador deste trabalho foi o marco inicial para buscar relatar esta experiência e socializar tanto para a comunidade cientifica, mas também para a comunidade como um todo.

Nesta conversa, Diegues (2017), relatou que o referido I encontro de Fandango que é objeto de analise deste artigo foi o "embrião de um grande processo de resgate da cultura do Fandango que anos mais tarde se vê presente em inúmeras manifestações nas comunidades e também em esforços institucionais como o importante projeto chamado Museu do Fandango, que 
inclusive foi bastante facilitado na realização dos seus objetivos tendo este encontro de Fandango na Ilha do Cardoso em São Paulo realizado"

Outros encontros de Fandango foram realizados anos mais tarde no município de Guaraqueçaba/PR, Paranaguá/PR e Cananeia/SP, tendo o encontro de 2008 em Guaraqueçaba/PR um marco histórico também importante, uma vez que foi apresentado ao IPHAN por meio de inúmeras associações de São Paulo e Paraná, NUPAUB/USP e outros institutos e organizações não governamentais, o pedido de registro do Fandango Caiçara como Patrimônio Cultural do Brasil (DIEGUES, 2013).

Como resultados imediatos deste evento que promoveu a reflexão e a importância da expressão cultural do Fandango foi a criação da Associação dos Fandangueiros de Cananeia e também dos Amigos da Cultura Caiçara também em Cananeia/SP que conforme relatos por membros destas instituições o encontro de Fandango na llha do Cardoso de 2003 "mexeu muito com o pessoal local".

A Casa do Fandango de Cananeia também teve sua origem nas primeiras conversas realizadas no encontro de Fandango da llha do Cardoso. A Casa do Fandango é um espaço de arte e cultura que buscar incentivar, valorizar e resgatar a cultura caiçara e realiza inúmeras oficinas de arte, música e danças típicas.

Também é possível observar inúmeros eventos de Fandango que vem sendo realizados pelo litoral Sul de São Paulo e Litoral Norte do Paraná como os pesquisados e registrados no quadro 01 abaixo entre outros e além das cantorias de Fandango informais em praças publicas ou bares que foram observadas pelo pesquisador deste artigo entre 2013 e 2017 em Antonina/PR, Matinhos/PR, Paranaguá/PR, Ilha do Superagui/PR e Guaraqueçaba/PR..

Quadro 1: Relação de ações que envolvem o Fandango como manifestação cultural local.

\begin{tabular}{|c|c|}
\hline Evento & Localidade \\
\hline I Festa do Fandango & Cananeia/SP \\
\hline Festa do Mar & Cananeia/SP \\
\hline Festa do Fandango & Paranaguá/PR \\
\hline Festa do Fandango & Guaraqueçaba/PR \\
\hline I Encontro de Fandango da Ilha do Cardoso & Parque Estadual Ilha do Cardoso, \\
& Cananeia/SP \\
\hline
\end{tabular}

\section{Grupos ativos}

É importante ressaltar que diversos grupos de Fandango estão ativos e especialmente formado por jovens como, por exemplo, o Grupo de Fandango do Prelado de Iguape/SP, Grupo Jovens da Juréia de Bertioga/SP, Grupo de Fandango Batido São Gonçalo, Caiçaras do Acaraú, Esperança, Família Neves, Família Pereira, Fandangueiros do Ariri, Fandangueiros do Continente, Jovens Fandagueiros do Itacuruça, Terra Firme, Viola de Ouro São Paulo Bagre de Cananeia/SP e no estado do Paraná os grupos Fandango Mestre 
Romão de Paranagua/PR, Fandango do Mandiguera da ilha dos Valadares/PR e Grupo Folclórico Caiçaras do Paraná de Paranagua/PR

\section{Conclusões}

Um momento de encontro como esse coloca todos em um mesmo tempo, harmoniza as pessoas envolvidas com uma mesma questão, o que potencializa as ações, definindo objetivos e direcionando os resultados. Percebe-se a bela interação entre as pessoas unidas pela cultura, as quais fazem dessa união um prazer, trazem força para traçar estratégias de continuidade para o Fandango e fazem com que fique evidente: "o Fandango está muito vivo".

Outra conclusão que se pode tirar é a tranformação pela qual o Fandango está passando. Saiu de uma época de maior envolvimento das pessoas com a vida em comunidade, de maior dependência da agricultura e maior valorização de culturas peculiares. Os aspectos citados eram laços seguros para o Fandango, um exemplo claro disso é a realização dos mutirões que ocorriam nas comunidades caiçaras. Toda finalização dos mutirões era marcada por uma festa de Fandango que durava a noite inteira, caracterizando a grande relação dessa arte com a roça, sustentando por muito tempo a prática do Fandango.

Atualmente, segundo Diegues (2019), o Fandango está em fase de adaptação ao novo contexto social. Essa nova realidade faz, por vários motivos já citados neste documento, as pessoas se inserirem em um estilo de vida moderno mais afastado da natureza, influenciadas por buscas pessoais diferentes das de antigamente e também por outras culturas que chegam de forma voraz pelos poderosos meios de comunicaçäo.

Os laços que garantem a sobrevivência do Fandango não estão mais diretamente ligados com necessidade rotineiras da comunidade e sim com necessidade da valorização da cultura tanto por parte das pessoas mais velhas que tem o domínio da arte, quanto por parte dos mais jovens, importantes na garantia de transmissão de conhecimento para as futuras gerações.

Fica claro em um encontro como esse que a cultura se transforma. O ser humano é o único animal que tem a capacidade de cultivar. O cultivo de uma expressão musical que envolve muitas famílias abre espaço para encontros comunitários em que, além de diversão, acontece discussão do cotidiano e busca de alternativas para a resolução de problemas comuns. A cultura aparece então, como veículo de comunicação entre as diferentes partes da comunidade, e pode ser transformada, mas não extinta.

A emoção de ver e de sentir a importância do Fandango para a região em que ele mais se expressa, pode ser visto sob dois pensamentos: o primeiro compreende todo o complexo, a relação de herança cultural, a diversidade musical, as relações entre as famílias e a consequente organização 
comunitária e união dos esforços. O outro pensamento é o da pessoa, a contribuição do Fandango para a sensibilidade artística, para a harmonia interior e para a auto estima, visível na alegria, no sorriso incandescente e na incansável vontade de tocar, dançar e cantar, cultivo humano de frutos musicais.

A valorização cultural promovida por este encontro de Fandango na Ilha do Cardoso é uma resistência aos grupos dominantes que usam seu poder para promover os seus próprios valores excluindo ou eliminando as demais subalternas. É importante que a manutenção e o cuidado com este patrimônio cultural e histórico do Brasil estejam guardados pelos próprios caiçaras seja pela oralidade ou por registros em teses, dissertações e ou outros documentos (FUNARI, 2001).

\section{Referências}

AB' SABER, N. Conceituando Educação Ambiental. Rio de Janeiro: Museu de Astronomia e Ciências Afins-CNPq, 1991.

BRITO, M. Elaboração Participativa de uma Agenda 21 Local da Comunidade Caiçara do Pouso da Cajaíba. Projeto de Pesquisa-Dissertação de Mestradoencaminhado à FAPESP, Piracicaba, ESALQ-USP, 1998.

CORRÊA, J.R.O. Museu Vivo do Fandango: um projeto em construção. In: DIEGUES, A.C. (org.). Enciclopédia caiçara, v.5: festas, lendas e mitos caiçaras. São Paulo: Hucitec/USP, Nupaub/CEC, 2006.

DENZIN, N. K.; LINCOLN, Y.S. Handbook of Qualitative Research. USA: Sage, 1994.

DIEGUES, A.C. (org). Enciclopédia Caiçara v.5: festas, lendas e mitos caiçaras. São Paulo, HUICITEC: USP, Nupaub/ CEC, 2006.

DIEGUES, A.C. O Mito Moderno da Natureza Intocada. 5 ediçao. São Paulo. Editora Hucitec/NUPAUB/USP, 2004.

DIEGUES, A.C. Conversa concedida à Amilcar Marcel de Souza, Curitiba, 25 de maio de 2017.

DIEGUES, A.C. O Fandango do Litoral Sul de São Paulo e Litoral Norte do Paraná Relato em Reunião para a elaboração do artigo Caminhos Percorrido pela Educação Ambiental para a Valorização Cultural em março de 2019.

DIEGUES, A.C.; COELHO, D.M.T. O Fandango caiçara como forma de expressão do patrimônio cultural do brasil. Iluminuras, Porto Alegre, v. 14, n. 34, p. 85-103, ago./dez. 2013

DIEGUES, A.C.; NOGARA, P.J.N. O Nosso Lugar Virou Parque. Estudo Socioambiental do Saco do Mamanguá, Parati/RJ. 3 edição. NUPALB/USP, 2005. 
FALEIROS, K.S. Relatório de Projeto de Extensão Universitária da ESALQ/USP, Resgate Sociocultural do Fandango na llha do Cardoso, 2003. Acesso ao relatório impresso no Laboratório de Educação e Política Ambiental em julho de 2019.

FRANCO, A. Ação Local. A nova política da contemporaneidade. Brasília: Instituto de Política, 1995.

FUNARI, P.P. Os desafios da destruição e conservação do património cultural no brasil. Trabalhos de Antropologia e Etnologia, Porto, 41, 1/2, 2001, 23-32.

GRAMANI, D.C. O aprendizado e a prática da rabeca no Fandango caiçara: estudo de caso com os rabequistas da família Pereira da comunidade do Ariri. Dissertação apresentada ao Programa de Pós-Graduação em Música, Departamento de Artes, Setor de Ciências Humanas, Letras e Artes, Universidade Federal do Paraná, Curitiba ,2009.

INSTITUTO DO PATRIMÔNIO HISTÓRICO E ARTÍSTICO NACIONAL DEPARTAMENTO DE PRATRIMÔNIO IMATERIAL COORDENADORIA DE REGISTRO. Fandango Caiçara: Expressões de um Sistema Cultural, 2011. Acesso em agosto de 2019. Disponível em http://portal.iphan.gov.br/ uploads/ckfinder/arquivos/Dossi\%C3\%AA\%20Fandango\%20Caicara.pdf

INSTITUTO DO PATRIMÔNIO HISTÓRICO E ARTÍSTICO NACIONAL. LEITE, Edson. Turismo Cultural e Patrimônio Imaterial no Brasil. São Paulo: ITERCOM, 2011.

MARTINS, P. Um Divertimento Trabalhado Prestígios e Rivalidades no Fazer Fandango da ilha dos Valadares. Dissertação de mestrado apresentada como requisito parcial para a obtenção do grau de Mestre em Antropologia Social. Programa de Pós-Graduação em Antropologia Social, Setor de Ciências Humanas, Letras ,Curitiba, 2006.

PARÂMETROS CURRICULARES TRANSVERSAIS (PCN). Temas Transversais (Quinta a Oitava Séries). Brasília, 1998.

SEGURA, D. S. B. Venturas e Desventuras da Educação Ambiental na Escola Pública: um estudo de experiências na zona leste de São Paulo. Tese de Mestrado. São Paulo, 1999.

VIEZZER, M.; OVALLES, O. Manual Latino-Americano de Educação Ambiental. São Paulo: Editora Gaia, 1995. 


\section{Apêndice I}

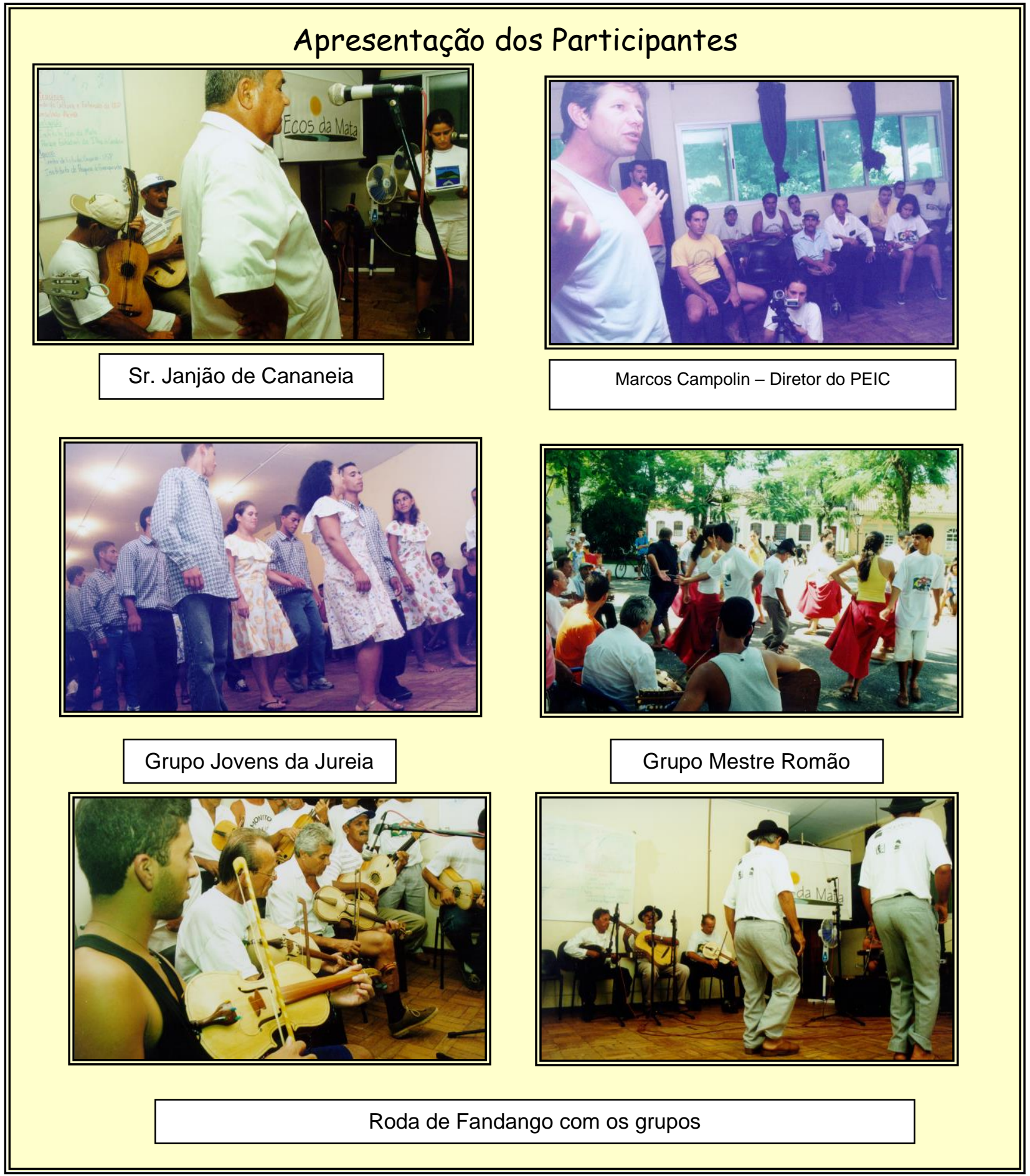

Fotos : Amilcar Marcel de Souza, 2003. 